\title{
Prensa política y libertad de expresión en la provincia de Córdoba en la segunda mitad del siglo XIX: la ley de imprenta de 1879
}

\author{
por \\ Laura Cucchi* \\ Universidad de Buenos Aires. Instituto Ravignani/CONICET
}

Este trabajo examina los debates que precedieron a la sanción de la ley de imprenta en Córdoba en 1879, con el objetivo de contribuir al estudio de los límites de la libertad de la prensa. Se presenta las características de las publicaciones locales y las normativas que regulaban su ejercicio y se explora las medidas oficiales tomadas para reprimir lo que se consideró sus abusos. Por último, se analiza los debates del poder legislativo sobre nueva reglamentación para este tipo de delitos, y se sugiere que en ellos no sólo se manifestaron diferencias respecto del grado de control que debia establecerse sobre las publicaciones sino también formas diversas de entender la prerrogativa popular de control de los actos de gobierno.

Palabras Clave: prensa política; Córdoba siglo XIX; oposición; libertad de imprenta; juicio por jurado.

\section{PRESENTACIÓN}

La sucesión presidencial de 1880 convulsionó la política argentina de finales de los años setenta desatando conflictos de amplias proporciones en

* Miembro del Proyecto Ubacyt: «Estado, política y ciudadanía en la Argentina de la segunda mitad del siglo XIX. Prácticas y representaciones».

Este trabajo forma parte de la investigación realizada para mi Tesis de Doctorado en Historia: "En un campo de Agramante. Antagonismo, legitimidad y poder en Córdoba entre 1877 y 1880", Universidad de Buenos Aires, 2011, realizada bajo la dirección de la Dra. Hilda Sabato. Deseo agradecer los comentarios del jurado integrado por la Dra. Gardenia Vidal, la Dra. Beatriz Bragoni y el Dr. Gustavo Paz. 
las provincias. En algunas de ellas, como Córdoba, se produjeron luchas armadas entre los partidarios de los dos candidatos a presidente: el gobernador de Buenos Aires, Carlos Tejedor, y el Ministro de Guerra, Julio Roca. Estas disputas condujeron a un enfrentamiento militar de amplias proporciones entre la provincia de Buenos Aires y las fuerzas nacionales, cuyo triunfo ha sido señalado como hito de la definitiva consolidación del poder del estado central sobre el conjunto de las provincias ${ }^{1}$.

En el umbral de ese conflictivo año Córdoba se dio su primera ley de imprenta desde la sanción de la Constitucional Nacional de 1853. Esa disposición se proponía regular las responsabilidades de los autores y publicaciones en casos de injurias o calumnias a magistrados, personas públicas y particulares, y buscaba principalmente mitigar las críticas de la prensa opositora a los miembros del gobierno de la provincia. La urgencia de las autoridades por sancionar una nueva normativa se vinculaba directamente con el conflicto político provincial y nacional, marcado por las diputas derivadas de la sucesión presidencial y la amenaza de un enfrentamiento armado. Puntualmente, el gobierno se proponía poner coto a la defensa, por parte de las publicaciones opositoras, del derecho de los ciudadanos a alzarse en armas contra la candidatura a presidente de Roca, que consideraban impuesta por el gobierno nacional y el provincial. En un sentido más ambicioso, la iniciativa oficial apuntaba a reformular el funcionamiento de la prensa política en la provincia, modificando los límites del ejercicio de la libertad de expresión y estipulando las responsabilidades penales de autores, editores e impresores.

El propósito de este trabajo es examinar los debates que acompañaron la sanción de la ley de imprenta de Córdoba de 1879, con el objetivo específico de analizar los proyectos de «pacificación» política y desmovilización ciudadana impulsados por el Partido Autonomista de esa provincia tras su ascenso al poder en 1877. Entre esas iniciativas se encontraba marcar límites más estrechos a la libertad de la prensa de promover acciones reñidas con el orden y la tranquilidad pública, que entroncaron con la agenda del Partido Autonomista Nacional que gobernó la Argentina a partir de 1880 bajo el lema «Paz y administración», y al que se integraron exitosamente las dirigencias autonomistas cordobesas, llegando uno de sus principales miembros, Miguel Juárez Celman, a la Presidencia de la República entre 1886 y $1890^{2}$.

En un sentido más amplio, este artículo aspira a contribuir al estudio del problema del control y los límites de la libertad de expresión de la prensa decimonónica. A lo largo del siglo XIX esa libertad se mantuvo como un

1 Halperin Donghi, 1995. Botana, 1998. Oszlak, 1999. Sabato, 2008.

2 Alonso y Ternavasio, 2011. 
principio indeclinable para la publicidad de los actos de gobierno y, así, para su fiscalización por parte del pueblo. Sin embargo, la articulación y difusión de los debates políticos por las publicaciones entraba en contradicción con extendidos anhelos de unanimidad y uniformidad de opiniones que las dirigencias señalaban necesarias para la consolidación de un orden político estable.

El trabajo está organizado de la siguiente manera. En primer lugar, se recupera el papel de la prensa en la dinámica política del Río de la Plata en la postindependencia, como espacio e instrumento de debate público. Se presentan, además, las características de las publicaciones cordobesas en los años setenta del siglo XIX y las normativas que regularon su ejercicio hasta 1879 . En segundo, se explora algunas medidas tomadas entre 1877 y 1880 por el gobierno provincial para reprimir lo que denunció como abusos de la prensa, tanto en el marco de juicios de imprenta, como de decretos de arresto de periodistas. Por último, se analiza los debates suscitados en la Legislatura respecto de la necesidad de una nueva reglamentación para juzgar delitos de imprenta, y se sugiere que en esas polémicas no sólo se manifestaron diferencias respecto del grado de control que debía establecerse sobre las publicaciones, sino que se presentaron también, en el marco de ellas, formas diversas de entender la prerrogativa popular de control y crítica de los actos de gobierno.

PRenSA y POLÍtica EN LA PROVINCIA

La prensa funcionó a lo largo del siglo XIX como una herramienta central en la definición y difusión de las polémicas políticas ${ }^{3}$. De la mano de ese ejercicio efectivo, ocupó también un lugar fundamental en los esquemas de organización republicanos, ya que fue considerada y se presentó a sí misma como ámbito de expresión de la elusiva figura de la «opinión pública», entendida como tribunal supremo en materia política. Tras la ruptura revolucionaria de 1810, la prensa materializó una de las instancias principales de control popular de los actos de gobierno, y con ello, de su legitimidad, al tiempo

3 Sobre la prensa política decimonónica en América Latina, especialmente: Jaksic (ed.), 2002. Alonso (comp.), 2004. Palti, 2005. Piccato, 2010. Fernández Sebastián (dir.), 2009; 2011. Para el Río de la Plata y Argentina: Duncan, 1980. Halperin Donghi, 1985. Myers, 2011. Alonso, 15 (Buenos Aires, 1997). Lettieri, 1999. Goldman, 4 (Bernal, 2000). Sabato y Lettieri, 2003. Bonaudo, 2005; LXVIII/ 242 (Madrid, 2008). González Bernaldo, 2008. Palti, 2009. Wasserman, 10 (San Pablo, 2009). Molina, 2009. Cucchi y Navajas, 82 (México, 2012). 
que aparecía simultáneamente, y en tensión, como espacio de libre intercambio de opiniones ${ }^{4}$. La importancia de ese ámbito de intervención pública fue consagrada en la Constitución Nacional que estableció el derecho de todo habitante de «publicar sus ideas por la prensa sin censura previa», y otorgó a las publicaciones la función de dar a conocer el proceso de formación y sanción de las leyes.

Las tensiones derivadas del ejercicio de esa amplia libertad se hicieron evidentes tempranamente. Las publicaciones expresaron y amplificaron los debates políticos y establecieron límites a la voluntad de las dirigencias de lograr convergencias en materia política que funcionaran como pilares para la conformación de un nuevo centro de autoridad en el Río de la Plata posrevolucionario. Por ello, procuraron regular esa libertad, marcando una distinción entre el uso legal de la prensa como espacio para el ejercicio del derecho de opinar libremente, y aquello que fue entendido como un uso ilegal. Esta última categoría abarcaba las ofensas a los particulares y a la religión católica, y los atentados a la constitución del estado y la tranquilidad pública. Esa diferencia estuvo presente en una de las primeras normas de este tipo, el decreto de libertad de imprenta de octubre 1811, y de allí en más, en las legislaciones que tipificaron los delitos de imprenta ${ }^{5}$.

Tras la reforma Constitucional de $1860^{6}$, la legislación quedó en manos de las provincias. Emulando la primera enmienda a la constitución de los Estados Unidos, se estableció que el Congreso Nacional no podía dictar leyes que restringieran la libertad de imprenta ni establecer jurisdicción federal sobre ella, cuestión que provocó polémicas acerca de la facultad de la justicia federal para juzgar los delitos de la prensa contra el orden, que se proyectaron hasta comienzos del siglo $\mathrm{XX}^{7}$.

4 Goldman y Pasino, 2008: 101. Sobre las formas de concebir la «opinión pública»a lo largo del siglo XIX argentino, ver además: Palti, 2009. Molina, 2009. Sabato, 2009.

5 Los contemporáneos no entendían que esa limitación de los abusos coartara la libertad de expresión, como resumía Facundo Zuviría sosteniendo que debía haber límites que reprimieran el uso abusivo de esa libertad cuando hollara otros derechos individuales, ya que a toda libertad correspondía una responsabilidad. Zuviría, 1857: 11-17, donde puede consultarse el texto del decreto (p. 164).

${ }^{6}$ Entre 1852 y 1861 el territorio del Río de la Plata estuvo dividido en dos estados nacionales: la Confederación Argentina y el Estado de Buenos Aires. La reforma constitucional de 1860 acompañó la incorporación del último a la Confederación, unificando así los dos estados, y se realizó a pedido de Buenos Aires que buscó garantizar su autonomía frente al gobierno nacional.

7 Vedia y Mitre, 1917. Eleodoro Lobos, 1897. Corte Suprema de Justicia de la Nación Argentina/Secretaría de Jurisprudencia, 2010: 1-6. 
La provincia de Córdoba dictó en 1852 un decreto reglamentando la libertad de la prensa que rigió, y se aplicó en los juicios de imprenta, hasta 1880. Esa disposición establecía que los particulares podían iniciar acusaciones contra publicaciones por calumnias o injurias, mientras que en casos de delitos contra la religión o el orden constituido correspondía a las autoridades provinciales iniciar las acciones correspondientes ${ }^{8}$. Precisamente los crímenes contra el orden estuvieron en la mira del gobierno provincial a finales de los años setenta, y llevaron a la sanción de la nueva reglamentación en 1879 .

En ese momento Córdoba desempeñaba un papel importante en los equilibrios políticos nacionales. Era la segunda provincia en población de la república, tras Buenos Aires, lo que le otorgaba un gran peso electoral ${ }^{9}$. En segundo lugar, ejercía una influencia no despreciable en las provincias ajenas al Litoral y había ocupado por ello un lugar destacado en las estrategias del gobierno nacional de integración y subordinación del Interior en pos de una unidad política efectiva ${ }^{10}$. Por último, en ella se articuló parte de los apoyos que en 1880 llevaron a la presidencia a Julio Roca, inaugurando la primera presidencia de 36 años de dominio del Partido Autonomista Nacional en la Argentina.

En los años sesenta se habían organizado dos partidos en Córdoba: el Nacionalista, vinculado al Partido de la Libertad de Buenos Aires (luego denominado Partido Nacionalista) que lideró la organización nacional entre 1862 y 1868 bajo la conducción de Bartolomé Mitre; y el Autonomista, que tomó ese nombre por su defensa de las prerrogativas provinciales frente al gobierno nacional. El autonomismo logró por primera vez la gobernación de Córdoba en 1877, de la mano de Antonio el Viso, y el nacionalismo, que había detentado el poder local hasta ese año, pasó a ejercer la oposición. Desde esa nueva posición, se sumó a la política nacional de Conciliación de los partidos con la esperanza de recuperar así una posición en el teatro político local.

La Conciliación fue promovida por el Presidente Nicolás Avellaneda en 1877 para lograr un acuerdo entre las dirigencias políticas del conjunto de las provincias respecto del candidato para sucederlo en la presidencia partir de 1880. Buscaba evitar, así, que la competencia electoral desatara conflictos

8 Galván Moreno, 1944: 353. Grenón, 1965: 16-17

9 La elección de Presidente y Vicepresidente era indirecta y se realizaba por medio de una Junta de 228 electores elegidos por las provincias. Córdoba contaba con algo más que el $11 \%$ de los electores, lo que la convertía en la segunda provincia en caudal electoral tras Buenos Aires. Botana, 1998: 88.

${ }^{10}$ Las autoridades nacionales tenían asiento en Buenos Aires. El resto del país estaba divido en la región del Litoral, a la que pertenecían Santa Fe, Entre Ríos y Corrientes, y el Interior, que correspondía al resto de las 14 provincias entre las que se encontraba Córdoba. 
armados, como había sucedido durante la elección que lo había llevado a la primera magistratura en 1874. En ese entonces, la candidatura de Avellaneda había contado con el apoyo del autonomismo porteño y un conjunto de dirigencias de otras provincias, pero no con la del nacionalismo de Buenos Aires liderado por Mitre, que organizó alzamientos en varias provincias bajo la demanda de «libertad electoral» ${ }^{11}$. Tras su derrota en manos del ejército nacional, el nacionalismo porteño dejó de participar en las elecciones que denunciaba como fraudulentas, socavando la legitimidad del gobierno nacional. Dada la amenaza potencial que esta posición opositora implicaba, el presidente promovió el acuerdo que se tradujo concretamente en la incorporación de opositores al gabinete nacional, y en la elaboración de listas conjuntas para algunas elecciones, como la de Gobernador de Buenos Aires de 1877 en la que triunfó Carlos Tejedor como candidato de conciliación.

Tras ese éxito inicial, Avellaneda procuró proyectar el acuerdo al resto del país, iniciativa que fracasó, pues la conciliación no suturó los enfrentamientos políticos en las provincias sino que, por el contrario, los multiplicó ${ }^{12}$. También en Buenos Aires condujo a una división del Partido Autonomista, que apoyaba al presidente, entre aquellos que se pronunciaron a favor y en contra del acuerdo. Por estos motivos, no se logró el objetivo principal de evitar la competencia electoral para las elecciones presidenciales de 1880, que fue disputada por los dos candidatos mencionados: Tejedor, promovido por los sectores que mantuvieron su apuesta por la Conciliación (el nacionalismo y parte del autonomismo) y Roca, sostenido por el sector del autonomismo que decidió no sumarse al acuerdo.

En Córdoba, la oposición nacionalista se alió a los conciliados de Buenos Aires y brindó su apoyo a Tejedor, mientras que el autonomismo que gobernaba la provincia sostuvo la candidatura de Roca. La competencia presidencial dividió así a los partidos locales, que, en la antesala de la sucesión de 1880, debían enfrentar otros importantes desafíos electorales, como la elección de un nuevo gobernador y de diputados nacionales, para lo cual se abocaron a la organización de sus recursos y solicitaron el apoyo material de sus aliados porteños. Las contiendas electorales se prepararon y definieron, también, en la prensa local, que organizó diferentes representaciones de la disputa entre nacionalistas y autonomistas. El funcionamiento de las publicaciones como ámbito y mecanismo privilegiado de constitución y expresión de las contro-

11 También en Buenos Aires los principales partidos se denominaban Nacionalista y Autonomista, y estaban comenzando en estos años a tejer puentes con los partidos de las demás provincias en pos de organizar fuerzas políticas de alcance nacional.

12 Paz, 2010. Cucchi y Navajas, 2012. 
versias entre las fuerzas políticas produjo desafíos constantes para la tramitación pacífica de la oposición, y los enfrentamientos de diferente envergadura que se dieron en el terreno electoral o en las cámaras provinciales se interpretaron y difundieron a través de las representaciones ofrecidas en la pren$\mathrm{sa}^{13}$.

Córdoba contó en el siglo XIX con casi dos centenares de publicaciones. En la primera mitad de la centuria, se editaron 35 periódicos, mientras que en la segunda aparecieron 155, de los cuales 91 que tuvieron una duración menor a un año, alrededor de 30 menor a dos años y 6 que duraron al menos tres años ${ }^{14}$. A finales de los años setenta se multiplicaron los periódicos en la ciudad y en algunos departamentos de campaña. Esas publicaciones convocaron a la movilización electoral, fueron escenario de fuertes disputas entre distintos representantes de los partidos y funcionaron además como importante punto de reunión e iniciación política para muchos jóvenes. Entre ellos se encontraron, El Pueblo Libre, La Situación, Los Principios, El Nacionalista, El Campesino, Pensamiento de Mayo, Moro Tarfe y El Huáscar, que reivindicaron su papel como órgano de difusión de las cuestiones políticas que esperaban el veredicto de «ese gran tribunal, el pueblo»y, por ello, como «barómetro exacto de la opinión pública» ${ }^{15}$. Las principales publicaciones continuaron siendo, sin embargo, las más antiguas: El Eco de Córdoba, La Carcajada y El Progreso, que, a diferencia de parte importante de la prensa del periodo, fueron empresas editoriales bastante sólidas y tuvieron más de quince años de trayectoria ${ }^{16}$.

El Eco de Córdoba fue fundado en 1862 por Ignacio Vélez y se publicó hasta 1886, participando de su redacción Luis Vélez, hermano del fundador y eminente político y académico local. En 1871 El Eco de Córdoba contaba con más de 500 suscriptores ${ }^{17}$. Aunque, según sus directores, el propósito principal del diario era la difusión de los principios católicos, su redacción se mantuvo abierta a la colaboración de autores liberales en materia religio-

13 En este sentido, el funcionamiento de la prensa política presentó en Córdoba desafíos similares para el procesamiento de la oposición y el desacuerdo a los que tuvieron lugar en otras provincias. Hemos realizado un trabajo comparativo entre la prensa cordobesa y tucumana en: Cucchi y Navajas, 2012.

14 Grenón, 1965; 1968. Bischoff, 1993. Vagliente, 2000: 48. Auza (ed.), 2002: 11. Ayrolo, 9-10 (Santa Rosa, 2005/2006): 21.

15 El Progreso, 6 de diciembre de 1877 y 17 de enero de 1878, respectivamente. Además, La Carcajada, 10 de marzo de 1878.

16 Para este trabajo se han utilizado estas tres publicaciones, dado que, además de ser las principales, son las únicas de la década de 1870 que se conservan (prácticamente completas).

17 Roitenburd, 2000: 39. 
$\mathrm{sa}^{18}$. Durante el primer gobierno autonomista (1877-1880), El Eco se convirtió en una firme voz opositora, en función del posicionamiento político de sus directores, y por los crecientes conflictos que se produjeron entre las autoridades civiles y eclesiásticas por las iniciativas laicistas que promovió el Poder Ejecutivo ${ }^{19}$.

En las filas opositoras militaba además Armengol Tercera, dueño del periódico jocoserio La Carcajada, también fuertemente crítico del gobierno autonomista. Fundado en 1871, se editó hasta fin de siglo regularmente, y luego de manera más esporádica hasta 1905. Ese semanario joco-serio no recibía subvención y contaba con alrededor de 300 suscriptores $^{20}$. Tecera tenía larga experiencia en el ámbito periodístico y en 1871 participó de la organización de la Sociedad Tipográfica de Córdoba, de la cual fue Vicepresidente desde 1878.

Por su parte, el principal referente autonomista fue el matutino El Progreso que contaba con alrededor de 500 suscriptores. Creado por Ramón Gil Navarro en 1867 , se editó hasta su muerte en 1884 y participaron de su redacción jóvenes universitarios que se vincularon a ese partido ${ }^{21}$. Este diario se presentaba como la voz «liberal» de Córdoba, llamada a polemizar con el «fanatismo religioso» de $E l E c O^{22}$.

Diarios y periódicos mantenían un diálogo constante entre sí y difundían la aparición de nuevas empresas editoriales, sus dificultades financieras y sus preferencias políticas. Los suscriptores solían recibir los números en sus casas, pero existían además varios puntos en la ciudad donde comprar ejemplares sueltos $^{23}$. La circulación era mayor a los ejemplares vendidos y las publicaciones se quejaban a menudo de «los lectores de arriba» que tomaban prestados números de sus vecinos o los consultaban en las confiterías, cafés y asociaciones, a lo que podría sumarse su circulación oral.

18 Auza, 2002: 284. Bischoff, 1993: 12. Córdoba era sede del Obispado homónimo y tenía una importante presencia institucional de la Iglesia Católica y de la religión en la vida pública.

19 Estas fricciones se originaron por la decisión del gobierno de poner bajo su autoridad un conjunto de esferas administradas por la Iglesia, como el registro de nacimientos y defunciones, la regulación de los matrimonios, el área educativa y los recursos de bienes de capellanías. Roitenburd, 2000.

20 Vagliente, 2000: 51.

${ }^{21}$ Gil Navarro fue diputado nacional por La Rioja y Córdoba, y diputado y senador provincial en esta última.

22 El Progreso, 14 de septiembre de 1877.

${ }^{23}$ La Carcajada, 22 de junio y 14 de septiembre de 1879. El Progreso, 3 de mayo de 1878. 
Esas publicaciones desempeñaron un lugar decisivo en las estrategias de los partidos provinciales. Convocaron a reuniones políticas, diseñaron y justificaron su accionar, y formularon y propagaron los elementos de presión y crítica a sus adversarios. Durante los meses de preparación para las elecciones de gobernador de 1879 y de presidente de 1880 la prédica crítica de las publicaciones opositoras se intensificó, acompañando la evolución de la política nacional. La disputa por la sucesión presidencial entre Roca y Tejedor se había agravado cuando el gobernador de Buenos Aires denunció que la candidatura del primero era apoyada por el gobierno nacional que buscaba imponer un sucesor para el Presidente Avellaneda. Por esas razones, Tejedor convocó a la ciudadanía a resistir por las armas ese avasallamiento del gobierno central, lo cual desató y profundizó el conflicto entre las autoridades nacionales y las de la mayor provincia ${ }^{24}$.

La prensa opositora de Córdoba se hizo eco del discurso de su candidato a presidente. Las publicaciones opositoras buscaron deslegitimar al gobierno nacional y al provincial denunciando un conjunto de abusos a los derechos ciudadanos, sobre todo en materia electoral, y sostuvieron que ello justificaba un levantamiento armado contra las autoridades ${ }^{25}$. Por su parte, la prensa oficialista criticó a la oposición por esa defensa del «derecho de revolución»e insistió por ello en la necesidad de establecer mayores límites al ejercicio de la libertad de expresión ${ }^{26}$. En ese marco, el diario vinculado al partido gobernante, $E l$ Progreso, reclamó una reforma de la legislación de imprenta, a la que caracterizó como insuficiente para contener la prédica subversiva del nacionalismo:

La libertad de imprenta ha sido tan bárbaramente interpretada, que algunos sicarios de la anarquía y del despotismo, se han abrogado el derecho de lanzar mofas sangrientas al rostro de personas respetables, y convirtiendo los deberes en derechos, se atreven pisotear las leyes, burlarse de las autoridades, y atacar a los más dignos y rectos magistrados, hasta en la vida privada... Es necesario que los gobiernos ilustrados, los cuales comprenden y hacen el bien de sus gobernados, no permitan semejante inmoralidad y tomen las medidas necesarias para evitar que ciertos pasquines inciten a la revuelta, pongan el desorden y lleven al país a la ruina. Es de urgente necesidad la reglamentación de las publicaciones diarias o periódicas, para evitar la corrupción en las masas ${ }^{27}$.

24 Sabato, 2008.

25 Entre otros, El Eco de Córdoba, 18 de febrero y 23 de octubre de 1879. La Carcajada, 19 de octubre y 30 de noviembre de 1879 .

26 Entre otros, El Progreso, 19 de septiembre de 1878; 11 y 30 de julio de 1879.

27 El Progreso, 13 de julio de 1879. Véase, además: El Progreso, 11 de enero y 23 de abril de 1878; 18 de diciembre de 1879 . 
LA NORMATIVA SOBRE LIBERTAD DE LA PRENSA ENTRE 1852 y 1880

La Constitución Nacional de 1853 estableció una muy amplia libertad de prensa. Sin embargo, como hemos mencionado, desde los tiempos de la independencia la legislación en esa materia contenía mecanismos para juzgar lo que presentaba como «abusos de la prensa», que se dividían en dos grupos: aquellos considerados subversivos y los que suponían una injuria a personas públicas o privadas. La normativa quedó en manos de las legislaturas provinciales, de modo que no existió legislación nacional sobre delitos de imprenta. Sin embargo, no todas las provincias sancionaron leyes de imprenta antes del periodo aquí abordado de 1880 .

Para 1879 regía en Buenos Aires un decreto provisorio de 1828 que incorporaba en parte disposiciones del mencionado decreto de libertad de imprenta de 1811 y de una ley posterior de 1822, aunque resultaba de carácter más restrictivo ${ }^{28}$. Esa reglamentación de finales de los años veinte establecía como abusos los ataques a la religión, la moral y la decencia pública, las ofensas al honor y a la reputación de un individuo, así como los escritos que promovieran la sedición o la alteración del orden. Estos delitos debían ser juzgados por un jury de 5 ciudadanos sacados a la suerte, que podían fijar multas de 500 a 2000 pesos, junto con la inhabilitación del editor o del impresor para garantir publicaciones por cuatro meses. En caso de insolvencia del condenado, se establecía pena de destierro de 4 a 12 meses en un pueblo de campaña ${ }^{29}$. En 1857 se dictó una nueva ley sobre injurias realizadas por la prensa, que se limitó a fijar que las acciones por calumnias, injurias o di-

28 Myers, 2011: 27. El decreto de octubre de 1811 ya mencionado establecía el derecho de todo hombre de publicar sus ideas sin censura previa. Afirmaba que el abuso de esa libertad constituía un crimen cuya acusación correspondía a los particulares si ofendía sus derechos, o a la ciudadanía en los casos en que atentara contra la tranquilidad pública, la constitución del estado o la religión católica. Por su parte, la ley provisoria de 1822 colocó el juzgamiento de estos delitos en el ámbito de la justicia ordinaria y estableció que debía participar del proceso 4 ciudadanos sacados a la suerte. Los textos del decreto y de la ley en Zuviría, 1857: 164-168.

${ }^{29}$ La ley de 1828 no tuvo una vigencia ininterrumpida hasta 1880 . Durante el régimen rosista (1829-1852), se establecieron nuevos límites a la prensa. El régimen político organizado por Rosas constituyó un ensayo de organización institucional de Buenos Aires y las «Provincias Unidas» que se configuró sobre la base de un centro de autoridad en la primera. Se organizó por medio de herramientas institucionales (como la acumulación de poder por parte del ejecutivo) y de prácticas tendentes a la eliminación o neutralización de los opositores, que se materializaron, entre otras disposiciones, en limitaciones legales a la prensa. A esas medidas, se sumaron otras restricciones prácticas y a menudo violentas, que coartaron seriamente el ejercicio de la libertad de expresión. Tras la caída del régimen, se restableció la ley 
famaciones podían resolverse indistintamente por jurados de imprenta o por los tribunales ordinarios, pero que no derogó las disposiciones de 1828 que siguieron aplicándose en los juicios de imprenta hasta el periodo aquí abordado de finales de los años setenta ${ }^{30}$.

También dictaron leyes de imprenta, desde la sanción de la Constitución Nacional y hasta la de la ley cordobesa aquí analizada, Santa Fe, San Juan, Mendoza y Tucumán, aunque la de esta última fue derogada en 1874. Las tres normativas provinciales que estaban vigentes en 1879 condenaban el uso «abusivo» de la libertad de la prensa, entre lo que consideraban escritos subversivos, sediciosos, e inmorales, así como aquellos que significaran una afrenta al honor (calumnias e injurias). Al igual que en Buenos Aires, esas regulaciones establecían el sistema de jurados para su juzgamiento y penas de multa o de prisión ${ }^{31}$.

En lo que respecta a Córdoba, la Constitución de 1870 estableció que la Legislatura no podía dictar leyes que contrariaran la libertad garantizada en la carta nacional. En relación con las responsabilidades de imprenta, fijó que las publicaciones que censuraran la conducta de personas públicas debían presentar pruebas que, de resultar ciertas, libraban a los autores de toda pena en las acciones que pudieran seguir contra ellos los magistrados que se hubieran considerado infamados. Posteriormente, la ley de organización de los tribunales de la provincia dispuso que el Fiscal del Estado podía iniciar de oficio procesos por abusos de la libertad de imprenta «con arreglo a la ley de la materia». Hasta ese momento, la reglamentación vigente consistía en el decreto de 1852, mencionado al comienzo de este trabajo, que disponía que el Fiscal sólo podía iniciar acción pública en casos de delitos contra la religión o el orden constituido, mientras que correspondía a los particulares entablar las acciones por calumnias o injurias ${ }^{32}$.

Este decreto fijaba que los responsables por abusos de imprenta eran los redactores o editores en caso que se atacara la religión del Estado, la vida privada del ciudadano, el sagrado derecho de la familia, o los principios proclamados por la República «como base de su organización nacional». Establecía, además, que en estos juicios debían entender los «Tribunales Ordina-

de 1828. Myers, 2011. Galván Moreno, 1944: 176-179. El texto de la ley en Zuviría, 1857: 169-172.

30 Myers, 2011: 131-132. El texto en Provincia de Buenos Aires, Recopilación... 1858: 863-864.

31 Galván Moreno, 1944. Bonaudo, LXVIII/242 (Madrid, 2008). Registro Oficial de la Provincia de Santa Fe, Santa Fe, tomos VIII y IX, 1889/1890. Provincia de Mendoza, 1860: 359-369.

32 Provincia de Córdoba, 1870, tomo 1: 154. Grenón, 1965: 16-17. 
rios, acompañados de dos ciudadanos elegidos por las partes». Entre 1857 y 1880 se entablaron sobre la base de esta reglamentación 52 juicios de imprenta contra 13 periódicos de la provincia, pero se mantuvo vigente la discusión sobre la necesidad de fijar con más claridad las responsabilidades de las publicaciones ${ }^{33}$.

Desde su ascenso al poder provincial en 1877, el Partido Autonomista buscó moderar el tono de los intercambios periodísticos, estableciendo, en primer lugar, que fueran publicados diariamente los actos de gobierno y los movimientos de tesorería en El Progreso, a quien subvencionó con ese fin. El objetivo de esta medida era dar cumplimiento al artículo $32^{\circ}$ de la Constitución Provincial que establecía el deber de publicar periódicamente a los actos oficiales (especialmente a los vinculados a la percepción e inversión de la renta), pero perseguía principalmente que la publicidad de sus disposiciones redundara en una prédica más moderada de la prensa opositora ${ }^{34}$.

En segundo lugar, el gobernador Antonio del Viso encomendó a las Cámaras elaborar una nueva ley sobre libertad de la prensa para corregir sus «abusos», que protegiera los derechos de aquellos injuriados o calumniados por ese medio. El Poder Ejecutivo proponía elaborar una nueva ley que estableciera que la responsabilidad podía recaer en el autor, o en su defecto en el impresor, y que fijara las penas correspondientes de acuerdo al «derecho común penal», tanto en los juicios por calumnias e injurias por la prensa, como en las acusaciones de oficio iniciadas por el Fiscal del estado en caso de que la publicación «insite a la subersión manifiesta del orden público» ${ }^{35}$. Con esa medida el gobierno buscaba superar las dificultades con las que se había encontrado en los juicios entablados desde 1877 contra algunas publicaciones. Desde ese año y hasta 1880 , se iniciaron más de una docena de juicios de imprenta en la Cámara del Crimen de la ciudad. La mayoría de ellos fueron iniciados por particulares que se consideraron injuriados por determinadas publicaciones $\mathrm{y}$, aunque se trató en general de acciones contra periódicos opositores, no faltaron las acusaciones de los dirigentes de estas filas contra el «oficial» El Progreso.

Los juicios se iniciaban cuando quienes se consideraban injuriados o calumniados acusaban a las publicaciones ante el Juez del Crimen. A partir de

33 Chaves, 1997: 77-80. Vagliente, 2000: 18.

34 Provincia de Córdoba, 1878: LXXXVI. "Mensage del Gobernador de la Provincia al abrir las sesiones legislativas de 1879", Ferreyra, 1997: 120. El Progreso, 28 de julio de 1878.

35 "Mensage del Gobernador de la Provincia al abrir las sesiones legislativas de 1879", Ferreyra, 1997: 120. 
allí comenzaba el proceso de averiguación del autor de las declaraciones denunciadas como infamantes. En primer lugar, se citaba al editor responsable de la publicación para que indicara quién había sido el autor de la nota. En ocasiones, el editor afirmaba que había sido él mismo, otras informaba la identidad el autor o sostenía desconocerlo. Una vez establecido quién había redactado las declaraciones en cuestión, el Juez del Crimen lo citaba para que asumiera las responsabilidades. A partir de allí se organizaba el juicio, nombrando cada parte un ciudadano como conjuez, de acuerdo a lo establecido por el decreto de 1852. Con el avance del proceso, muchas veces se llegaba a un acuerdo entre las partes o se establecía que las acusaciones por la prensa habían sido mutuas, ya que el autor del suelto había publicado en un periódico y la supuesta víctima de las declaraciones infamantes había respondido de la misma manera desde otra publicación. En esas ocasiones, también solía llegarse a un compromiso y concluía la causa. En otras, era necesario probar si las acusaciones hechas por la prensa eran ciertas o no, porque de ello dependía que el periodista o autor en cuestión fuese declarado culpable. Cuando esto resultaba imposible, se lo sobreseía por falta de pruebas. Si, por el contrario, se lograba establecer que el autor del suelto había realizado sus acusaciones sin fundamentos, debía abonar una multa que podía ser saldada con días de arresto ${ }^{36}$.

En relación a las dificultades para juzgar este tipo de delitos apuntadas por el gobernador del Viso, el problema principal radicaba en que se dilataban los procedimientos por las complicaciones a la hora de establecer quién era el

36 Juicio de imprenta contra El Jaspe por injurias al ex Jefe Thiriot, Expte. 1877-383-4; José Olmedo contra El Progreso por publicaciones, Expte. 1878-386-1; Santiago Díaz contra El Nacionalista, Expte. 1878-394-2; Dres. Oliva Clodomirdo y Castellanos Temístocles contra Pedro A. Gartland por injurias por la prensa, Expte. 1878-396-6; Antonio Mir contra Severo Obregón por injurias por la prensa, Expte. 1878-399-5; José C. Funes contra El Progreso, Expte. 1879-400-6; Contra El Pueblo Libre por injurias a Manuel Pizarro, Expte. 1879-40310; Contra Domingo Mendoza por injurias por la prensa a Pedro y Domingo Funes, Expte. 1879-404-9; Guillermo A. Moyano contra El Pueblo Libre por publicaciones, Expte. 1879406-3; Calderon Juarez contra El Pueblo Libre por publicaciones, Expte. 1879-406-4; Angulo y García contra El Progreso por injurias y calumnias, Expte. 1879-406-12; Angulo y García contra don Guillermo Moyano y Don Cipriano Soria por injurias y calumnias, Expte. 1879-406-13; Rafael Yofre contra El Pueblo Libre, Expte. 1879-408-3; Santiago Cáceres contra Emilio Sanchez por publicación injuriosa, Expte. 1880-417-4. Todos los expedientes en la Cámara del Crimen de la Ciudad Capital, Archivo Histórico de Córdoba. Excede los límites de este trabajo una presentación detallada de los juicios en cuestión, que están siendo analizados en el marco de una investigación en curso. En la Argentina, no se cuenta con estudios específicos sobre los juicios de imprenta en la segunda mitad del XIX, salvo exploraciones preliminares realizadas en Navajas, 2011. García Garino, 2012. 
autor del artículo en cuestión ${ }^{37}$. El gobierno proponía por ello que, de no poder establecerse la identidad del autor, la acusación recayera directamente en el impresor del periódico. Los tres principales periódicos de la provincia contaban con imprenta propia, pero no así las publicaciones menores que debían contratar este servicio ${ }^{38}$, de manera que, con esta medida, el gobierno buscaba que los impresores se negaran a publicar hojas que pudieran dar lugar a juicios de imprenta.

El segundo problema indicado por el Poder Ejecutivo era establecer con precisión cómo debían aplicarse las penas en cada caso, y abogaba por la eliminación del fuero especial que protegía a la prensa hasta ese momento, y que estipulaba la participación de un ciudadano por cada parte en el juicio. Esto resultaba un cambio sustantivo en la regulación de la prensa, ya que sometía los delitos cometidos en ella a los tribunales ordinarios ${ }^{39}$. La propuesta del gobierno apuntaba así a fortalecer el papel del estado provincial en el control de este ámbito, así como a subsanar las dificultades que había encontrado en procesos iniciados durante estos años. Estas se habían hecho especialmente manifiestas en un juicio que el Poder Ejecutivo entabló contra $L a$ Carcajada, a la que acusó de haber calumniado al gobierno e instigado a la rebelión a través de la calificación de la nueva administración como «gobierno de hecho» ${ }^{40}$.

El juicio había sido iniciado tras un enfrentamiento violento entre Tecera, dueño de ese periódico, y un miembro importante de las filas autonomistas, Antonio Rodríguez del Busto. El incidente se había desatado cuando Rodríguez del Busto increpó al periodista por haberlo llamado «ladrón» en su semanario y le pidió «satisfacción inmediata». Ante la negativa, «el Sr. Rodríguez lo abofeteó de la forma más espléndida llevándolo a trompadas...» y le advirtió «que si alguna vez volvía a aludirle en su inmundo pasquín no solo le rompería las narices, como lo acababa de hacer, sino que lo había de matar como a un perro», según el relato de El Progreso que defendía ese comportamiento como forma de obtener una reparación más inmediata de la que podría lograrse por un juicio de imprenta con la deficiente reglamentación

37 Ha sido señalado que determinar el autor de los escritos acusados constituía el mayor obstáculo en estos juicios, y que parte importante de esos procesos judiciales estaba destinada a hacer pública la identidad y responsabilidad del autor. Piccato, 2004: 146.

38 Grenón, 1965.

39 Los intentos de contener lo que se presentaba como «abusos» de la libertad de imprenta buscaron avanzar, por lo general, en esta dirección. Piccato, 2004. Wasserman, 10 (San Pablo, 2009). Gantús, 2009.

40 Entre otros, La Carcajada, 3 de agosto de 1878; 23 de noviembre de 1879. 
vigente desde $1852^{41}$. Como saldo del enfrentamiento, el propietario de La Carcajada debió pagar una multa de diez pesos por escándalo y pelea.

El periodista denunció en su publicación que el ataque sufrido demostraba la voluntad de un gobierno tirano decidido a terminar con la libertad de la prensa y las garantías individuales ${ }^{42}$. El Poder Ejecutivo inició entonces el proceso contra la publicación por medio del Fiscal del estado. La defensa de Tecera estuvo a cargo del abogado y periodista opositor, Miguel Angulo y García, quien fundó su exposición ante el jurado en dos puntos. En primer lugar, buscó demostrar que las acusaciones del periódico eran verdaderas, porque en la provincia efectivamente tenía lugar un gobierno tirano por sus formas de ejercicio del poder. En ese sentido, sostuvo, no se podía acusar a La Carcajada de la acción de calumnia que consistía en «la falsa imputación de un delito criminal», dado que la publicación se había limitado a sostener afirmaciones verdaderas. En segundo lugar, Angulo argumentó que las personas jurídicas no eran pasibles de sufrir el delito de calumnia, y que tampoco podía imputarse el de injuria, que era uno de carácter privado. El jurado, compuesto por Juan del Campillo, Pablo Julio Rodríguez y José Echenique, falló a favor de la publicación, sosteniendo la falta de personería del Fiscal para acusar a publicaciones en nombre del Poder Ejecutivo, y por la incapacidad de éste en carácter de persona jurídica de ser calumniado como tal ${ }^{43}$.

Las denuncias opositoras de «persecución oficial» a la prensa aumentaron cuando el Poder Legislativo tomó medidas contra otro periódico opositor, El Pueblo Libre, en mayo y octubre de 1879. Esas consistieron en diez días de arresto en el primer caso y de treinta en el segundo, y los periodistas penados fueron dos referentes de la oposición: Lucas López Cabanillas y el editor responsable del periódico, el ya mencionado abogado Miguel Angulo y García. En los dos casos, la Cámara de Diputados apeló al artículo $85^{\circ}$ de la Constitución Provincial que establecía que el Poder Legislativo podía ordenar el arresto de personas que ofendieran a la Cámara ${ }^{44}$, y afirmó que el diario había difamado «sin consideración alguna a miembros todos del Poder Legislativo sin tomar en cuenta ni su posición ni sus servicios prestados al país por $\operatorname{largos}$ años $\rangle^{45}$.

41 El Progreso, 13 de marzo de 1878.

42 La Carcajada, 24 de marzo de 1878.

43 Ibidem, 12 de mayo de 1878.

44 Melo, 1950: 174.

45 Honorable Cámara de Diputados de la Provincia de Córdoba, Córdoba, Argentina (en adelante, HCDPC), $6^{\circ}$ Sesión, $1^{\circ}$ Ordinaria, 15 de mayo de 1879 , Actas de Sesiones de la Cámara de Diputados, 1879, tomo 8, Archivo de la Honorable Legislatura de la Provincia de Córdoba, Córdoba, Argentina (en adelante, AHLPC), folios 340-342. HCDPC, Sesiones Se- 
La prensa autonomista respaldó tanto el decreto de la Cámara de Diputados como la propuesta del gobernador de reformar la legislación provincial y remitió a la incesante prédica de los diarios opositores, que amparados en «la suma libertad de imprenta», predicaban la legitimidad de una salida armada al conflicto partidario provincial e instigaban al pueblo a alzarse contra las autoridades legales. Por esos motivos, El Progreso publicó varias editoriales en las cuales no negaba la centralidad de la libertad de imprenta, pero presentaba lo que consideraba abusos cometidos en su nombre en toda la Repúbli$\mathrm{ca}^{46}$.

Por su parte, los periódicos opositores combatieron la propuesta del gobernador de reformar la legislación de imprenta con varios argumentos. En primer lugar, remitieron a la Constitución nacional y a la provincial y afirmaron que cualquier restricción a la libertad de la prensa resultaba contraria a los postulados de los artículos 31 de la primera y 41 y 42 de la segunda, tanto «porque la Constitución no quiere limitar, quiere garantir la libertad de imprenta», como porque la propuesta de que en caso de no ser pagada la multa por el autor o editor responsable, esta pudiera ser ejecutada sobre la imprenta misma constituía una violación de los derechos de propiedad ${ }^{47}$. En segundo lugar, aludieron al papel de la prensa como «cuarto poder», encargado de fiscalizar los actos de gobierno ${ }^{48}$, y sostuvieron que en, tanto encarnación de la opinión pública, su deber era «juzga(r) a los mandatarios del pueblo, en nombre de este». Las publicaciones opositoras revindicaron así su papel de controlador del accionar del gobierno, sobre todo en esta hora decisiva en que, a su juicio, estaban desapareciendo de la provincia todos los derechos y garantías del ciudadano. Afirmaron por ello que, en ese contexto alarmante, la prensa como agente «censor» del gobierno constituía «el recurso único que queda a los pueblos oprimidos y vejados para elevar sus quejas $\mathrm{y}$ formular sus protestas» ${ }^{49}$.

cretas, Sesión del 31 de Octubre de 1879, Actas de Sesiones Secretas, AHLPC, folios 28. Sobre los sucesivos arrestos de Angulo y García: El Eco de Córdoba, 20 de mayo y 27 de noviembre de 1879, entre otros. Sobre el de López Cabanillas: El Progreso, 5 de diciembre de 1879. Angulo y García, 1883: 317-318.

46 Entre otros, El Progreso, 8 de mayo de 1878; 13 de julio y 16 de diciembre de 1879.

47 Angulo y García, 1883: 382. El Eco de Córdoba, 28 de agosto de 1879.

48 Con ese fin habían solicitado al Poder Legislativo la publicación de todos los proyectos presentados a las cámaras, para que pudieran ser estudiados por los periódicos y difundidos al público. El Eco de Córdoba, $1^{\circ}$ de julio de 1879.

49 El Eco de Córdoba, 28 de agosto y 12 de septiembre de 1879. Angulo y García, 1883: 31 . 
LA SANCIÓN DE UNA NUEVA LEY DE IMPRENTA: CONTROVERSIAS

EN LA LEGISLATURA

El proyecto de ley de imprenta impulsado por el gobierno fue presentado por los diputados autonomistas Figueroa, Moyano y Serna el 30 de julio de 1879 y pasó a la comisión de Legislación. El 18 de agosto, la comisión presentó su despacho a la Cámara, que finalmente lo trató el 5 de septiembre tras la insistencia del ministro de Gobierno, Miguel Juárez Celman, que se presentó en el recinto y participó activamente del debate. El diputado Moyano fundó el proyecto remitiendo a la necesidad de sancionar una ley de imprenta para establecer las responsabilidades en esa materia y el procedimiento que debía seguirse cuando se iniciaran procesos por «abusos de esta libertad». La iniciativa fue votada en general y los diputados hicieron observaciones de forma a cuatro artículos que finalmente no sufrieron modificaciones ${ }^{50}$.

El proyecto establecía que los periódicos debían contar un editor que estaría obligado a responder en los juicios, en los casos que no pudiera establecerse la identidad del autor. Asimismo, fijaba que las publicaciones debían dar cuenta del nombre de la imprenta que tendría la misma responsabilidad que el editor. Si este no saldara las multas recibidas, éstas podrían ejecutarse directamente sobre la imprenta, o, si su valor no fuera suficiente, con días de arresto. Clarificaba, además, lo establecido en la Constitución provincial, marcando las diferencias entre las personas públicas y las privadas. En el caso de las primeras, el proyecto establecía que debía seguirse un juicio ordinario para probar los hechos denunciados por la publicación, que, de ser probados, liberaban de toda culpa al autor del suelto. En caso contrario, esto es, si se probaba que los hechos denunciados eran falsos, el autor debería pagar una multa de 10 a 500 pesos fuertes. En el caso de las personas privadas, el autor o editor sería castigado con una multa equivalente y no se admitiría prueba sobre los hechos denunciados. El autor o editor debía pagar las costas del juicio tanto en el primer como en el segundo caso.

El procedimiento debía iniciarse con una acusación ante el juez del Crimen y se resolvería con una audiencia. En el caso que las calumnias o injurias fueran mutuas, el juez podía imponer el mínimo de la pena a las dos partes. Los demás artículos establecían las penas en casos de reincidencia, los pro-

50 HCDPC, $19^{\circ}$ Sesión, $14^{\circ}$ Ordinaria, 5 de septiembre de 1879 , Actas de Sesiones de la Cámara de Diputados, tomo 8, 1879, AHLPC, folios 168-176. 
cedimientos para presentar apelaciones y derogaban las demás leyes o disposiciones en lo que se opusieran a esta ${ }^{51}$.

Tras ser aprobada por la Cámara de Diputados la propuesta fue enviada al Senado. La Comisión de Legislación de esta cámara, integrada por los senadores opositores Gil, Leyba y Silveira, la rechazó porque, a su juicio, constituía una restricción a la libertad de imprenta vigente y, además, por diferencias doctrinarias en relación a las formas de juzgar delitos de imprenta. Esta comisión elaboró un nuevo proyecto sustancialmente distinto donde se distinguía las publicaciones «de carácter sedicioso», que debían ser juzgadas por los tribunales ordinarios, y las causas por delitos de imprenta que debían resolverse en juicios por jurados. El jury de imprenta debía componerse en cada caso por 5 ciudadanos designados a tal efecto de una lista de contribuyentes que debían renovarse anualmente. No podían ser convocados para este servicio los empleados a sueldo del Poder Ejecutivo nacional ni provincial, los condenados o procesados por delitos con pena corporal, los menores de 22 años, quienes no supieran leer y escribir o quienes fueran propietarios de imprentas, editores o redactores de publicaciones periódicas, ni quienes no pagaran contribución directa o patente por valor al menos de 30 pesos fuertes. De no se cumplir con esta obligación, los convocados debían ser sancionados con penas pecuniarias o 30 días de arresto en el Departamento de Policía, puesto que este servicio era considerado carga pública. En los casos en los que los jurados tuvieran dudas sobre la aplicación de la ley de imprenta, podrían consultarlo con el Juez del Crimen que estaba a cargo del proceso, pero la sentencia debía ser dictada por los jurados y la condena ser resuelta entre ellos por mayoría absoluta.

Los senadores fundaron este proyecto sosteniendo que «todas las Naciones civilizadas, para esta clase de juicios, habían establecido el Jurado porque querían alejar todo pretesto o motivo de corrupción a la Justicia ordinaria» ${ }^{52}$. Esta distinción resultaba clave para comprender las diferencias entre la propuesta de diputados y la de senadores, que no sólo buscaban establecer distintos grados de control sobre la prensa, sino que además, en un sentido más general, promovían formas diversas de entender la prerrogativa popular de control y crítica de los actos de gobierno.

51 Honorable Cámara de Senadores de la Provincia de Córdoba, Córdoba, Argentina (en adelante, HCSPC), Notas y proyectos, tomo 7. Archivo del Senado 1878-1879, AHLPC, folios 459-462.

52 HCSPC, Sesión del 20 de noviembre de 1879, Copias de Actas de las Sesiones Públicas, tomo 7, 1878-1881, AHLPC, folios 157-165. 
Ha sido sugerido que el sistema de juicio por jurados fue una de las cuestiones de índole procesal con mayor carga ideológica en el derecho argentino del XIX ${ }^{53}$. Desde el periodo revolucionario se debatió, en diversas coyunturas, la posibilidad de establecer una mayor participación popular en al administración de justicia, para garantizar la nueva igualdad ante la ley así como el poder judiciario del pueblo. En este sentido, esa institución se vinculaba con el principio de retroversión de la soberanía popular, como «fundamento de la libertad y de la salud pública», y en carácter de tal fue incorporado por la reforma judicial de Buenos Aires de 1821 para el juzgamiento de delitos de imprenta ${ }^{54}$.

Posteriormente, la institución del jury fue mencionada en tres artículos de la Constitución Nacional de 1853, que fijaban que debía ser establecida por el Poder Legislativo ${ }^{55}$. En las décadas siguientes se presentaron varios proyectos en el Congreso para hacer efectivo este sistema, pero ninguno fue aprobado. En 1871 se dictó una ley nacional que organizaba una comisión, integrada por el constitucionalista Florentino González y por Victorino de la Plaza, para que elaborara el proyecto de ley respectivo ${ }^{56}$. El servicio de jury fue entonces defendido, entre otros, por los senadores Bartolomé Mitre y Salustiano Zavalía, quienes lo definieron, respectivamente, como «dogma para todo pueblo libre» y «complemento del sistema democrático» ${ }^{57}$ en la medida en que representaba una de las dimensiones de las libertades y derechos ciudadanos y se correspondía de esa manera con los principios de todo gobierno republicano. En ese sentido, esta institución «del pueblo, y para el pueblo», podía considerarse un complemento del derecho de sufragio, ya que si por este, «el pueblo participaba en la formación de la ley», como jurado «podía tener parte también en su aplicación $»^{58}$.

La propuesta elaborada por González y Plaza finalmente no fue tratada por las cámaras, y el establecimiento del sistema de juicio por jurados quedó

53 Levaggi, 7 (Valparaíso, 1982).

54 Candioti, 3 (Buenos Aires, 2008). Padilla Arroyo, 47 (México, 2000): 138.

55 Alberdi, 1980: 313, 320 y 330, respectivamente.

56 Florentino González publicó en 1869 un estudio que circuló por América Latina, titulado: El juicio por jurados, Buenos Aires, Imp. Lit. y Fundición de tipos a vapor, 1869. Cuatro años después publicó, junto al otro miembro de la comisión, Victorino de la Plaza el Proyecto de ley sobre el establecimiento del juicio por jurados y de código de procedimiento criminal en las causas que conoce la justicia nacional, Buenos Aires, Imprenta y Librería de Mayo, 1873.

${ }^{57}$ Las citas de Mitre y Zavalía han sido tomadas de Barrancos y Vedia, 2005, tomo XXXII.

58 González, 1897: 672. 
pendiente y perdió adeptos sobre el fin de siglo con la difusión de la escuela positiva de derecho penal y la puesta en cuestión de los modelos de organización republicana fundados en una alta participación ciudadana que habían tendido apoyos extendidos de una parte de la clase política argentina hasta 1880 .

De todas maneras, en varias provincias como Santa Fe y Buenos Aires, funcionaron en estos años sistema de juicios por jurados, aunque únicamente para delitos de imprenta ${ }^{59}$. Lo mismo sucedió en otros países de América Latina, en los cuales aunque no se incorporara o no se hiciera finalmente efectivo este sistema para los juicios penales, sí funcionó para los de imprenta $^{60}$. Varios gobiernos posrevolucionarios de la región reservaron al nuevo pueblo soberano el derecho de juzgar el ejercicio de una libertad fundamental en los nuevos esquemas políticos republicanos como lo era la de expresión, y alejar así toda posibilidad de una ejecución arbitraria de las leyes relativas a la prensa. En Chile se formaron jurados populares para entender en esta clase de delitos hasta 1925, como también lo hicieron en México, donde fueron suprimidos durante el Porfiriato en 1883; en Venezuela funcionaron hasta 1888 y fueron restablecidos en el cambio de siglo; mientras que Paraguay contó con ellos hasta los años treinta del siglo $\mathrm{XX}^{61}$.

Emulando la Carta nacional, la Constitución cordobesa de 1870 incorporó el sistema de jurados, fijando que los juicios criminales ordinarios se «terminarán por Jurados», una vez que el Congreso de la Nación estableciera esta institución ${ }^{62}$. Pero como el Legislativo Nacional no avanzó en ese sentido, el debate en relación a la introducción de jurados populares continuó, con diferentes grados de intensidad, hasta el siglo $\mathrm{XX}^{63}$. De todas maneras, en los juicios de imprenta se aplicaba hasta el momento la normativa de 1852 que había establecido que su juzgamiento debía realizarse en los tribunales ordinarios, por el juez correspondiente y la participación de dos ciudadanos como conjueces, como ya fue mencionado. La propuesta de la Comisión de Legislación del Senado buscaba entonces ampliar esta participación de dos a cinco

\footnotetext{
59 Levaggi, 7 (Valparaíso, 1982): 199 y 217.

60 Ha sido señalado que esa distinción podía remontarse a la Constitución de Cádiz que había establecido el sistema de jury sólo en materia de imprenta. Bonaudo, LXVIII/ 242 (Madrid, 2008): 273-274. González Oropeza, 2 (México, 2000): 83.

61 Véase para Argentina: Levaggi, 7 (Valparaíso, 1982). Barrancos y Vedia, 2005, tomo XXXII. Bonaudo, LXVIII/ 242 (Madrid, 2008). Para México: González Oropeza 2 (México, 2000). Padilla Arroyo, 47 (México, 2000). Piccato, 2004. Para Chile: Piwonka Figueroa, 19 (Santiago de Chile, 1999); 20 (Santiago de Chile, 2010). Para Paraguay: García Bordón, 2005.

62 Melo, 1950: 187.

63 Scarsini, 13 (Buenos Aires, s/f).
} 
ciudadanos, haciéndose eco de la experiencia de otras provincias en esta materia ${ }^{64}$, y resultaba el primer intento de sancionar un sistema de jurados populares para delitos de imprenta en Córdoba.

El proyecto comenzó a ser discutido el 20 de noviembre de 1879. En esa ocasión, volvió a presentarse en el recinto el ministro de Gobierno, Miguel Juárez Celman, para defender el proyecto original de Diputados. Juárez sostenía que este resultaba más completo, ya que establecía que la pena recaería en última instancia en la imprenta, lo que salvaba el recurso de muchos autores que ponían como responsables de la publicación «a changadores o sirvientes». También el senador autonomista Ángel Sosa defendió esa versión por la necesidad «imperiosa» de sancionar una ley en esa materia. En su opinión, por lo avanzado del periodo de sesiones no sería posible que la cámara baja evaluara el nuevo proyecto elaborado por la Comisión de Legislación del Senado. Por estos motivos, afirmó:

Que aun suponiendo que fuese defectuosa la sancionada ya [por Diputados], era indiscutible que sería más conveniente el aceptarla definitivamente antes que quedarse sin ley al respecto porque no podía considerarse como tal la existente. Que la única diferencia radical que se notaba en los proyectos, era que el uno establecía el Jurado y el otro dejaba a la justicia ordinaria el entender en estos juicios.

A continuación, el senador opositor Gil condenó severamente la posición de Sosa como la del ministro Juárez Celman, así como la inclusión de cualquier artículo que estableciera que la pena podría ejecutarse sobre la imprenta, que «aparte de ser injusto, era atacar directamente el medio más poderoso de civilización». La polémica se vio interrumpida cuando otro senador opositor, Manuel Amuchástegui, se retiró abruptamente de la sesión dejando a la cámara sin quórum. En la siguiente sesión del 13 de diciembre de 1879, el autonomismo consiguió quórum con sus propias filas y terminó de rechazar el proyecto del Senado y, una vez más con las observaciones insistentes de Juárez, aprobó el elaborado por la Cámara de Diputados ${ }^{65}$.

Las diferencias entre las dos propuestas eran sustantivas. El proyecto de Diputados, que había sido elaborado por la dirigencia autonomista, buscaba juzgar las causas de imprenta de acuerdo al fuero común y, contrariamente al decreto de 1852 y a la propuesta del Senado, no especificó diferencias entre 1876.

${ }^{64}$ Este proyecto resultaba particularmente similar a la ley de imprenta santafecina de

65 HCSPC, Sesiones del 20/11 y 13/12/1879, Copias de Actas de las Sesiones Públicas, tomo 7, 1878-1881, folios 157-167; "Ley 797 determinando las responsabilidades consiguientes a los delitos de imprenta”, Provincia de Córdoba, 1916: 268-271. 
los delitos por abusos de imprenta (contra el orden constituido) y los delitos comunes que podían realizarse por medio de la prensa (de calumnias e injurias), opacidad que redundaba en un mayor recorte del margen de acción de la prensa. La nueva ley eliminaba las formas de organizar el jurado que obedecían al fuero especial otorgado a la prensa en el decreto de 1852, por el cual hasta el momento habían entendido en el proceso el Juez y dos ciudadanos. Establecía, también, penas más duras a las vigentes, puesto que la posibilidad de que éstas se ejecutaran directamente sobre las imprentas (en caso de no poder establecerse la identidad del autor del suelto), podía traducirse en el cierre de algunas publicaciones o la negativa de los propietarios de imprenta de brindar sus servicios a determinados periódicos.

Por el contrario, el proyecto defendido por la oposición, elaborado por la Comisión de Legislación del Senado, fijaba penas significativamente menores para este tipo de delitos. Establecía la mitad de días de arresto para saldar las multas, y alivianaba los castigos para los casos de reincidencia. Defendía, además, un fuero especial para los delitos realizados por la prensa, ampliando lo establecido por el decreto de 1852, ya que no se limitaba a otorgar el derecho de cada parte de nombrar un ciudadano como conjuez, sino que buscaba organizar directamente jurados de imprenta, esto es, que este tipo de delitos fuera juzgado por ciudadanos.

La promoción del establecimiento de esa institución no sólo implicaba una protección para uno de los principales mecanismos de control popular de los actos gubernamentales como lo era la prensa. Suponía, también, una apuesta por una mayor participación ciudadana, puesto que el servicio de jury podía brindar un espacio para la socialización política y para la transmisión de una educación cívica, ya que podía instruir «al pueblo en la práctica y los ejercicios de la democracia» ${ }^{66}$. Esta propuesta procuraba, por otra parte, establecer una valla contra la posibilidad de un ejercicio arbitrario de la ley, al disponer el derecho de los ciudadanos a ser juzgados por sus pares y evitar de esa manera que la justicia en esa materia quedara solo en manos del estado. Significaba, por último, un fortalecimiento de las atribuciones de fiscalización del accionar de los gobiernos por parte de los ciudadanos que iba más allá de la libertad de publicación y que podía contribuir al control de la independencia del Poder Judicial respecto del Ejecutivo. En este sentido, la defensa de esta institución podía remitir a formas específicas de entender el ejercicio de la ciudadanía en el marco de alegatos más generales de los diputados y senadores del nacionalismo en favor de esquemas de funcionamiento de las instituciones provinciales en las que el control de un ejercicio legítimo del poder

66 Padilla Arroyo, 47 (México, 2000): 138. 
político estuviera asegurado sobre la base de una activa participación ciudadana, que podría vincularse a lo que Natalio Botana ha denominado una organización republicana sustentada en la movilización cívica ${ }^{67}$.

Por estos motivos, las publicaciones opositoras condenaron duramente la nueva ley de imprenta que colocaba los procesos en el ámbito de los tribunales ordinarios y recortaba el margen de acción de las publicaciones. La Carcajada se preguntó cómo la prensa podía ejercer su función de censurar los actos de gobierno y marcarle el camino que debía seguir, si acto seguido iba a ser enjuiciada. Por este motivo, este periódico comparó la situación en la que se encontraba la provincia, en relación con la vigencia de libertades y garantías, con aquella imperante bajo régimen rosista ${ }^{68}$.

La nueva reglamentación no aplacó las acusaciones realizadas por los periódicos opositores. Su condena del gobierno como «nueva tiranía» fue acompañada de la defensa del derecho del pueblo a combatir en el terreno de las armas en favor de sus libertades. Esta retórica se intensificó tras la derrota de la oposición en la elección de gobernador que condujo a un levantamiento armado que este sector impulsó en febrero de 1880 para terminar con el dominio autonomista de la provincia. Con esa acción armada, la oposición buscaba además evitar que el partido gobernante pusiera todos los recursos de la provincia a favor de la elección de la candidatura presidencial de Roca. Como saldo del alzamiento, la nuevamente derrotada oposición se encontró, en víspera de las elecciones presidenciales de abril de 1880, con sus principales líderes enjuiciados y las imprentas de los diarios opositores destruidas a manos de militantes autonomistas ${ }^{69}$.

\section{REFLEXIONES FINALES}

La dinámica de la prensa como espacio de debate público y herramienta política generó en Córdoba desafíos similares a los que presentó en el resto de las experiencias republicanas del XIX. Su consideración de encarnación de la opinión pública y, como tal, juez de los actos de gobierno, condensó en las

\footnotetext{
67 Botana, 1984: 381-382.

${ }^{68}$ La Carcajada, 21 de diciembre de 1879. Ver además: El Eco de Córdoba, 23 de diciembre de 1879. Sobre el régimen rosista ver nota 29.

69 La oposición denunció nula la elección de gobernador por la falta de garantías para el ejercicio de la libertad electoral y se levantó en armas el 26 de febrero de 1880, con el apoyo en hombres, armas y recursos de sus aliados de Buenos Aires. He explorado el alzamiento y las acciones seguidas por los militantes autonomistas contra las imprentas de los diarios que apoyaron el levantamiento en Cucchi, 2012.
} 
publicaciones periódicas las tensiones derivadas de las prerrogativas populares de fiscalización del accionar de los mandatarios y la voluntad de estos de controlar, a su vez, los discursos que pudieran resultar en menoscabo de su poder. Esta tensión se materializó en la distinción entre un uso legal y uno ilegal de la libertad de expresión que fue retomada por todas las reglamentaciones de imprenta elaboradas por las provincias, dada la ausencia de jurisdicción federal en esa materia.

En el periodo aquí analizado se produjo en Córdoba un cambio sustantivo en la normativa que pautaba la libertad de la prensa de la mano de la primera ley de responsabilidad de imprenta que la provincia sancionó en la experiencia constitucional. Esta nueva reglamentación impulsada por el autonomismo provincial perseguía varios objetivos. En el nivel más inmediato, buscaba acotar los márgenes de acción de la oposición y desarticular un tipo de periodismo político que el partido gobernante consideraba «de barricada» ${ }^{70}$. En un sentido más ambicioso, procuraba un fortalecimiento de la autoridad de estado provincial. En función de ello, ese sector insistió en colocar el juzgamiento de los delitos de imprenta en el fuero común, y rechazó un sistema de jurados como el vigente en otras provincias que, por el contrario, apuntaba al fomento de una mayor participación ciudadana y a una ampliación de sus mecanismos de control del poder.

En el contexto de virulentos enfrentamientos partidarios, el autonomismo condenó la prédica habitual de las publicaciones, para señalar lo que juzgaba como una falla más general de las reglas de la política tal y como se practicaba en la provincia, y que a su juicio suponía atentados constantes contra el principio de autoridad. La reforma para «contener» los abusos del ejercicio de la libertad de imprenta participaba de esa manera de una avanzada más general del partido por terminar con formas de ejercicio político que suponía asociadas a ese estilo de periodismo. El autonomismo apostó por una pacificación de los enfrentamientos partidarios en la provincia, a la que asoció con una desmovilización, con la clausura de prácticas de alta participación cívica que eran defendidas por el nacionalismo, y que habían caracterizado la dinámica política nacional de las últimas décadas ${ }^{71}$. En ese sentido, la contienda sobre los límites de la libertad de la prensa de Córdoba podría formar parte de un combate más general respecto de las formas aceptables de ejercicio político y organización republicana, que excedía los límites provinciales. En este terreno se dieron pasos decisivos en los enfrentamientos armados de 1880 en Buenos Aires y, tras ellos, en el triunfo de las nuevas formas de adminis-

70 El Progreso, 19 de septiembre de 1878.

71 Cucchi, 2011. 
tración del poder que caracterizaron la política argentina en los años que sucedieron $^{72}$.

\section{BiBLIOGRAFÍA}

Angulo y García, Miguel, Homoousios, o consubstancialidad cordobesa. Entre el editor de una publicación i el autor. Sancionada en la lei de imprenta de 1879 por los tiranuelos Antonio del Viso i Miguel Juárez Celman, Córdoba, 1883.

Alberdi, Juan Bautista, Bases y puntos de partida para la Organización Politica de la República Argentina, Buenos Aires, Plus Ultra, 1980.

Alonso, Paula, "En la primavera de la historia.. El discurso político del roquismo de los años ochenta a través de su prensa", Boletín del Instituto de Historia Argentina y Americana «Dr. Emilio Ravignani», 3ra. serie, 15 (Buenos Aires, 1997): 35-71.

Alonso, Paula (comp.), Construcciones impresas. Panfletos, diarios y revistas en la formación de los estados nacionales en América Latina 1820-1920, Buenos Aires, FCE, 2004.

Alonso, Paula y Ternavasio, Marcela, "Liberalimo y ensayos políticos en el siglo XIX argentino", Iván Jaksić y Eduardo Posada Carbó (eds.), Liberalismo y poder. Latinoamérica en el siglo XIX, Santiago de Chile, FCE, 2011: 279-319.

Auza, Néstor Tomás, Archivo de Ignacio Vélez. Director de El Eco de Córdoba. 18641888, Buenos Aires, Dunken, 2002.

Ayrolo, Valentina, "Noticias sobre la opinión y la prensa periódica en la Provincia autónoma de Córdoba: 1820-1852", Quinto Sol, 9-10 (Santa Rosa, 2005/2006): 1346.

Barrancos y Vedia, Fernando, "El Juicio por jurados", Anales de la Academia Nacional de Ciencias Morales y Políticas, XXXII (Buenos Aires, 2005): 1-12.

Bischoff, Efraín, Política y buen humor en el periodismo cordobés (siglo XIX), Córdoba, Junta Provincial de Historia de Córdoba, 1993.

Bonaudo, Marta, "De la opinión publicada a la opinión pública. La prensa como lugar de representación y conflicto", Marta Bonaudo (dir.), Imaginarios y prácticas de un orden burgués, Rosario, 1850-1930, Rosario, Prohistoria ediciones, 2005: 71-96.

Bonaudo, Marta, "Aires gaditanos en el mundo rioplatense. La experiencia de los jefes políticos y el juicio por jurados en tierras santafesinas (segunda mitad del siglo XIX)", Revista de Indias, LXVIII/242, (Madrid, 2008): 255-280. 2008.

72 Botana, 1984; 1998. Halperin Donghi, 1995. Alonso, 15 (Buenos Aires, 1997). Sabato, 
Botana, Natalio, La Tradición Republicana. Alberdi, Sarmiento y las ideas políticas de su tiempo, Buenos Aires, Sudamericana, 1984.

Botana, Natalio, El Orden Conservador. La politica argentina entre 1880 y 1916, Buenos Aires, Sudamericana, 1998.

Candioti, Magdalena, "Fueros, jueces y jurados: el debate público en torno a la reforma judicial rivadaviana", Papeles de Trabajo. Revista Electrónica del IDAES, 3 (Buenos Aires, 2008): 1-19.

Chaves, Liliana, Tradiciones y rupturas de la élite política cordobesa (1870-1880). La clave conservadora de la modernización política, Córdoba, Ferreyra Editor, 1997.

Corte Suprema de Justicia de la Nación Argentina/Secretaría de Jurisprudencia, Libertad de Expresión, Buenos Aires, Presidencia de la Nación, 2010.

Cucchi, Laura, "En un campo de Agramante': antagonismo, legitimidad y poder en Córdoba entre 1877 y 1880", tesis de doctorado inédita, Universidad de Buenos Aires, 2011.

Cucchi, Laura, "Desacuerdo y oposición política en Córdoba a fines de la década de 1870", Estudios Sociales. Revista Universitaria Semestral, 42 (Santa Fe, 2012): 57-90.

Cucchi, Laura y Navajas, María José, “Un actor 'incómodo’: prensa política en Córdoba y Tucumán a fines de la década de 1870. Discursos, prácticas y representaciones", Secuencia, 82 (México D.F., enero-abril 2012): 41-71.

Díaz de Molina, Alfredo, La oligarquía argentina. Su filiación y su régimen, 1848-1898, Buenos Aires, Ediciones Pannedille, 1972.

Duncan, William Timothy, "La prensa política: 'Sud-América', 1884-1892", Gustavo Ferrari y Ezequiel Gallo (comps.), La Argentina del ochenta al centenario, Buenos Aires, Sudamericana, 1980: 761-781.

Fernández Sebastián, Javier (dir.), Diccionario político y social del mundo iberoamericano. Conceptos políticos en la era de las revoluciones, 1750-1850, Madrid, Fundación Carolina/Sociedad Estatal de Conmemoraciones Culturales, Centro de Estudios Políticos y Constitucionales, 2009.

Fernández Sebastián, Javier, "Toleration and Freedom of the Expression in the Hispanic World between Enlightenment and Liberalism", Past \& Present, 211 (Oxford, 2011): 159-197.

Ferreyra, Ana Inés, Mensajes de los gobernadores de Córdoba a la legislatura, tomo III: 1871-1885, Córdoba, Centro de Estudios Históricos, 1997.

Galván Moreno, Celedonio, El periodismo argentino: amplia y documentada historia desde sus orígenes hasta el presente, Buenos Aires, Claridad, 1944.

Gantús, Fausta, Caricatura y poder político. Crítica, censura y represión en la ciudad de México, 1876-1888, México, COLMES/Instituto Mora, 2009. 
García Bordón, Eduardo A., Juicio por Jurados en el Paraguay, Asunción, GTZ/Ministerio Público, 2005.

García Garino, Gabriela, "Honor y libertad de prensa: dos procesos judiciales por injurias. (Mendoza, 1860)", Estudios Avanzados, 17 (Santiago de Chile, 2012): 63 86.

Goldman, Noemí, "Libertad de imprenta, opinión pública y debate constitucional en el Río de la Plata (1810-1827)", Prismas. Revista de Historia Intelectual, 4 (Bernal, 2000): 9-20.

Goldman Noemí y Pasino, Alejandra, “Opinión pública”, Noemí Goldman (ed.), Lenguaje y Revolución. Conceptos políticos clave en el Río de la Plata, 1780-1850, Buenos Aires, Prometeo, 2008: 99-113.

González, Joaquín V., Manual de la Constitución Argentina, Buenos Aires, Estrada, 1897.

González Bernaldo, Pilar, Civilidad y política en los orígenes de la Nación Argentina. Las sociabilidades en Buenos Aires, 1829-1862, Buenos Aires, FCE, 2008.

González Oropeza, Manuel, "El Juicio por Jurado en las Constituciones de México”, Cuestiones Constitucionales, 2 (México, 2000): 73-86.

Grenón, Pedro, La tercera imprenta de Córdoba de medio siglo, 1850- 1900, Córdoba, Imprenta Gutenberg, 1965.

Grenón, Pedro, Medio siglo de periodismo cordobés (los de la tercera imprenta), Córdoba, Universidad Nacional de Córdoba, 1968.

Halperin Donghi, Tulio, José Hernández y sus mundos, Buenos Aires, Sudamericana, 1985.

Halperin Donghi, Tulio, Proyecto y Construcción de una nación (1846-1880), Buenos Aires, Ariel, 1995.

Jaksić, Iván (ed.), The Political Power of Word. Press and Oratory in Nineteenth Century Latin America, London, Institute of Latin American Studies, 2002.

Lettieri, Alberto, La República de la Opinión. Política y opinión pública en Buenos Aires entre 1852 y 1862, Buenos Aires, Biblos, 1999.

Levaggi, Abelardo, "El Juicio por Jurados en la Argentina durante el siglo XIX”, Revista de Estudios Histórico Jurídicos, 7 (Valparaíso, 1982): 175-218.

Lobos, Eleodoro, "Legislación de imprenta”, Jorge Navarro Viola, Anuario de la Prensa Argentina 1896, Buenos Aires, Imprenta de Pablo E. Coni e hijos, 1897: 29-50.

Melo, Carlos R. (ed.), Constituciones de la Provincia de Córdoba, Córdoba, Imprenta de la Universidad, 1950. 
Molina, Eugenia, El poder de la opinión pública. Trayectos y avatares de una nueva cultura política en el Río de la Plata, 1800-1852, Santa Fe, Universidad Nacional del Litoral, 2009.

Myers, Jorge, Orden y virtud. El discurso republicano en el régimen rosista, Bernal, Universidad Nacional de Quilmes, 2011.

Navajas, María José, "Libertades individuales versus autonomías provinciales: debates en la prensa porteña a finales de la década del 80", VI Jornadas Nacionales: Espacio, Memoria, Identidad, Rosario, Universidad Nacional del Litoral, 2011.

Oszlak, Oscar, La formación del Estado argentino. Orden, progreso y organización nacional, Buenos Aires, Planeta, 1999.

Padilla Arroyo, Antonio, "Los jurados populares en la administración de justicia en México del siglo XIX”, Secuencia, 47 (México D.F., 2000): 137-170.

Palti, Elías José, La invención de una legitimidad. Razón y retórica en el pensamiento mexicano del siglo XIX. (Un estudio sobre las formas del discurso político), México, FCE, 2005.

Palti, Elías José, El momento romántico. Nación, historia y lenguajes políticos en la Argentina del siglo XIX, Buenos Aires, EUDEBA, 2009.

Paz, Gustavo, "Años turbulentos. Política provincial e instituciones nacionales, Jujuy 1875-1880", Beatriz Bragoni y Eduardo Míguez (coords.), Un nuevo orden político: provincias y Estado Nacional, 1852-1880, Buenos Aires, Biblos, 2010: 159-179.

Piccato, Pablo, "Jurados de imprenta en México: el honor en la construcción de la esfera pública, 1821-1882", Paula Alonso (comp.), Construcciones impresas. Panfletos, diarios y revistas en la formación de los estados nacionales en América Latina, 1820-1920, Buenos Aires, FCE, 2004: 139-166.

Piccato, Pablo, The Tyranny of Opinion: Honor in the Construction of the Mexican Public Sphere, Durham, Duke University Press, 2010.

Piwonka Figueroa, Gonzalo, "Prensa periódica y libertad de imprenta: 1823-1835", Cuadernos de Historia, 19 (Santiago de Chile: 1999): 79-112.

Piwonka Figueroa, Gonzalo, "Los juicios por jurado en Chile", Revista Chilena de Historia del Derecho, 20 (Santiago de Chile, 2010): 133-146.

Provincia de Buenos Aires, Recopilación de las leyes y decretos promulgados en Buenos Aires desde enero de 1841 a la fecha, Buenos Aires, Imprenta de Mayo,1858.

Provincia de Córdoba, Compilación de leyes, decretos, acuerdos de la Excelentísima Cámara de Justicia y demás disposiciones de carácter público dictada en la Provincia de Córdoba desde 1810 a 1870, Córdoba, Imprenta el Estado, 1870.

Provincia de Córdoba, Leyes de la Provincia de Córdoba: leyes $N^{\circ} 718$ a 814: año 1876 a 1880, Córdoba, Imprenta Pablo Aubinel y Cía, 1916. 
Provincia de Córdoba, Memoria presentada a la Honorable Legislatura de la Provincia de Córdoba por el Ministro de Gobierno, Dr. D. Juárez Celman, Córdoba, Imprenta del Eco de Córdoba, 1878

Provincia de Mendoza, Código de las leyes, decretos y acuerdos que sobre la Administración de Justicia se ha dictado en Mendoza, Mendoza, Imprenta de El Constitucional, 1860.

Roitenburd, Silvia N., Nacionalismo católico. Córdoba (1862-1943). Educación en los dogmas para un proyecto global restrictivo, Córdoba, Ferreyra Editor, 2000.

Román, Claudia Andrea, "La prensa satírica argentina del siglo XIX. Palabras e imágenes", tesis de doctorado inédita, Universidad de Bueno Aires, 2011.

Sabato, Hilda, Buenos Aires en armas. La revolución de 1880, Buenos Aires, Siglo XXI, 2008.

Sabato, Hilda, "El pueblo 'uno e indivisible’. Prácticas políticas del liberalismo porteño", en Lilia Ana Bertoni y Luciano de Privitellio (comps.), Conflictos en democracia. La vida política argentina entre dos siglos, Buenos Aires, Siglo XXI, 2009.

Sabato, Hilda y Lettieri, Alberto (comps.), La vida política en la Argentina del siglo XIX. Armas, votos y voces, Buenos Aires, FCE, 2003.

Scarsini, Adriana, Juicio por Jurado, Buenos Aires, Editorial Fondo Jurídico, 1962. Serie Estudios e Investigaciones, n. ${ }^{\circ} 13$.

Vagliente, Pablo, Indicios de modernidad. Una mirada sociocultural desde el campo periodístico en Córdoba (1860-1880), Córdoba, Alción Editora, 2000.

Vedia y Mitre, Mariano, La libertad de imprenta y la jurisprudencia nacional, Buenos Aires, Imprenta de Coni Hnos., 1917.

Wasserman, Fabio, "La libertad de imprenta y sus límites: prensa y poder político en el Estado de Buenos Aires durante la década de 1850", Almanack Braziliense, 10 (San Pablo, 2009): 130-146.

Zuviría, Facundo, La prensa periódica, Montevideo, Imprenta de la República, 1857.

Fecha de recepción: 12 de marzo de 2012.

Fecha de aceptación: 17 de octubre de 2012. 


\section{Political Press and Freedom of Expression in Córdoba during the Second Half of the 19th Century: the Printing Press Law of 1879}

This paper explores the public debate that preceded the enactment of the 1879 Press Law in Córdoba, aiming to contribute to the study of the limits of freedom of the press. It describes the characteristics of local publications, the rules regulating the exercise of such freedom, and examines the official action taken to quell what were considered as its abuses. Finally, it analyses the Legislature debates on new regulations governing this type of offence, and suggests that they revealed differences not only regarding the degree of control that should be established for the publications but also diverse opinions about the right of the people to control government action.

KeY WORDs: political press; XIX century Córdoba; opposition; Freedom of the press; jury system. 